\title{
Biomimetic synthesis of nazlinin and nitrarine
}

\author{
M.J. Wanner and G.J. Koomen* \\ Laboratory of Organic Chemistry, University of Amsterdam. \\ Nieuwe Achtergracht 129, 1018 WS Amsterdam, The Netherlands.
}

\begin{abstract}
The presence of rather complicated alkaloids in Nitraria species as racemates suggests a non-enzymic biosynthesis of the skeletons, which implies that these reactions should be reproducible in the lab. In the case of Nitramine and Nitraramine the total synthesis was approached starting from highly symmetric glutarimide derivatives. Insight in the biosynthesis of Nitraria alkaloids led to a revision of the structure of Nazlinin. In the case of Nitrarine it was shown that spontaneous cyclizations to the racemic alkaloid skeleton occurred once the reactive precursor, containing an imine and an enamine functionality was treated with acid.
\end{abstract}

A variety of alkaloids has been isolated from different species of the Nitraria family (1). An interesting feature of these alkaloids is the fact, that they are isolated as racemates, even in cases where the molecule contains four or five stereocenters (2). This has been observed before for alkaloids like akuammicine (3), yuehchukene (4) and lucidene (5). Although it is generally assumed that plant enzymes play a role in all biosynthetic steps in the plants (6), it has been suggested before, that in some cases a nonenzymatic pathway cannot be excluded $(3,5)$. This would imply that at a certain point in the evolution of the plant, more or less by coincidence very reactive molecules are formed which give rise to the spontaneous formation of complex alkaloid skeletons as racemates. In later stages the plant might selectively convert one of the enantiomers into chiral products or enzymatically destroy an enantiomer. Viewed in this way the presence of racemic alkaloids in plants would imply, that these plants are in relatively early stages of their development.

The purpose of our research is to show that once the correct reactive biosynthetic precursors are prepared, the formation of the racemic alkaloids can also be achieved in the laboratory under more or less biological conditions.<smiles>C1=NCC([C@H]2CCCCN2)CC1</smiles>

1<smiles>C[C@@]1([C@@H](C=O)CCCN)CCCCN1</smiles>

chiral 2<smiles>NCCCCC1CCC=NC1</smiles>

achiral 4<smiles>OCC1CCCN2CCCC[C@H]12</smiles>

Lupinine 3

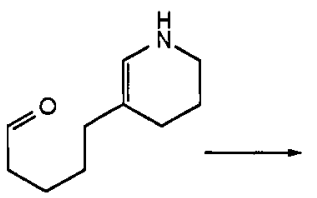

5

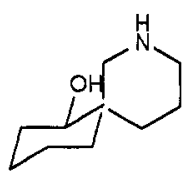

Nitramine 6

\section{SCHEME 1}

Nature is capable of producing an immense variety of products based on a very small number of building blocks. In the case of Nitraria alkaloids like Nitramine one can envisage a biosynthesis, based on lysine, via two units of piperidein, leading to tetrahydroanabasine 1 . Opening the ring via 1 (scheme 1) leads to the lupine alkaloids (6,7), whereas retro-Michael reaction via 4 , followed by oxidation and hydrolysis to $\underline{5}$ seems an attractive route to the racemic spirocyclic Nitraria alkaloids.In fact, reactive biodegradation products of amino acids thus lead to alkaloid synthesis. 
In view of the well-known instability of piperidein, in first instance we carried out the biomimetic synthesis using glutarimide synthons. Thus when $\mathbf{Z}$, obtained via a Wittig reaction with glutaric aldehyde (7) was treated with a nucleophile-Lewis acid combination it indeed cyclized to the Nitramine spiro skeleton. Three reduction steps yielded Nitramine 10 (7). (scheme 2)

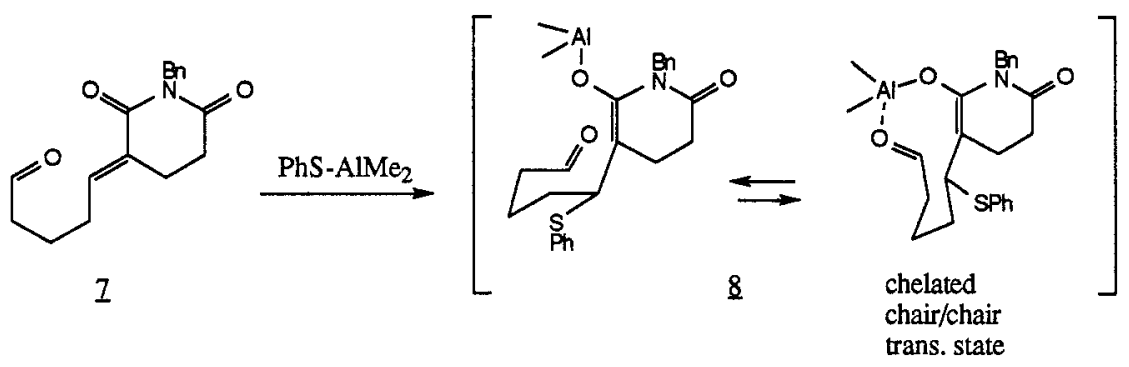

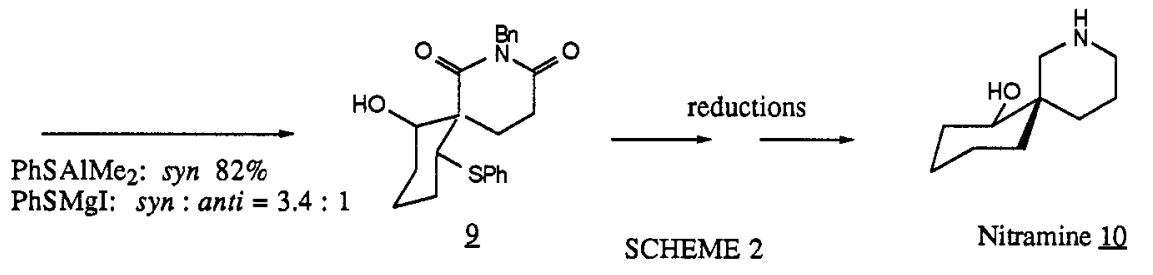

The formation of the more complex alkaloid Nitraramine, despite its six stereocenters present in Nitraria Schoberi as a racemate can be envisaged from the highly symmetrical $11\left(\mathrm{C}_{2 \mathrm{v}}\right)$. Also in this case, a single step gives rise to the formation of 13 in good yield. The remaining steps have not been achieved yet, partly due to the wrong oxidation state of the glutarimide synthons. If the correct oxidation state can be obtained, the last step should be a spontaneous acid catalyzed cyclization (7). In the required conformation of 14 however, both substituents should occupy axial positions.

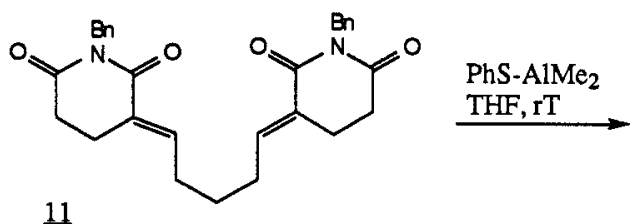

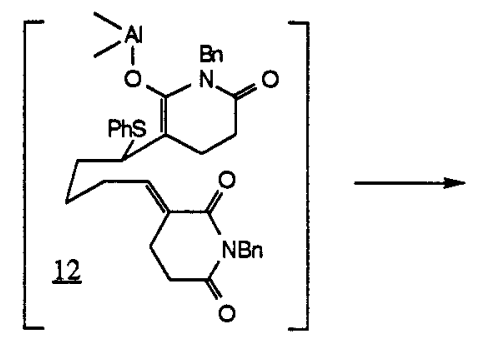

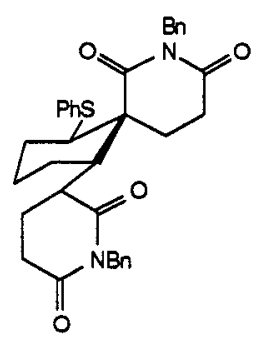

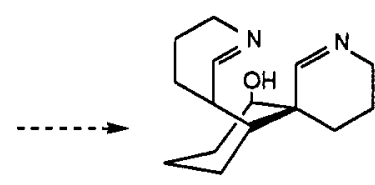

14

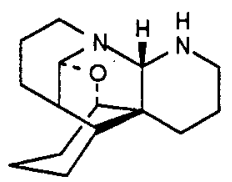

Nitraramine 15

13 ca $70 \%, 2$ isomers.

SCHEME 3

In view of the problems associated with the high oxidation state of glutarimide synthons, we have directed our attention in several syntheses to the more labile piperidein and other imine-enamine synthons.

Recently, the alkaloid Nazlinin was also isolated from Nitraria Schoberi as a racemate. On the basis of spectral data the authors assigned structure 16 to the molecule (8). This is puzzling, since it is not obvious how 16 could be generated from tryptamine and piperidein, especially bearing in mind that an optically inactive product suggests a non enzymatic route to its formation. A reaction of tryptamine with piperidein, obtained by us in situ under acid conditions from its stable trimer, yielded $17(72 \%)$ with the same molecular formula and the same spectral characteristics as those 
reported. Unequivocal structural proof was obtained from the ${ }^{1}$ H-NMR spectra of the diacetylderivative, which showed the presence of the $\mathrm{CH}_{2}-\mathrm{NHAc}$ moiety in Nazlinin (9). With a co-factor analogue Nazlinin could be cyclized to 18 which upon reduction produced 19 , another alkaloid known to be present in Nitraria as a racemate.<smiles></smiles><smiles>CCCCCC1NCCc2c1n([TlH])c1ccccc21</smiles><smiles>NCCc1c[nH]c2ccccc12</smiles><smiles>C1=NCCCC1</smiles>

Nazlinin 17

SCHEME 4<smiles>c1ccc2c3c([nH]c2c1)C1CCC[CH+]N1CC3</smiles>

$\underline{18}$<smiles></smiles>

$\underline{19}$

To obtain additional evidence for our suggestion that spontaneous cyclization of reactive molecules can lead to rather complex racemic alkaloids, we turned our attention towards Nitrarine 27, isolated as a racemate from Nitraria Schoberi and Nitraria komarovii (2b). The ultimate reactive precursor 20 (scheme 5) of the alkaloid, containing an imine and an enamine function indeed under acidic conditions cyclized to give two isomers of Nitramidine 21 and 22 (The presence of Nitramidine in the plants has been established). The isomer, thus obtained to our knowledge has not been reported (yet?).<smiles>C=C=C</smiles>

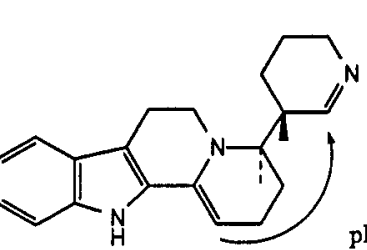

pH-dependent imine/enamine equilibrium determines the ratio of isomers<smiles>C1=NCCC/C1=C\CC/C=C1\NCCc2c1[nH]c1ccccc21</smiles>

Achiral precursor 20

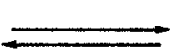

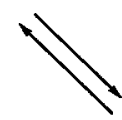<smiles>C1=C2c3[nH]c4ccccc4c3CCN2C(C23CCCCCCCC2CCCC3)=CC1</smiles><smiles>[Y][V]</smiles>

$3: 5$

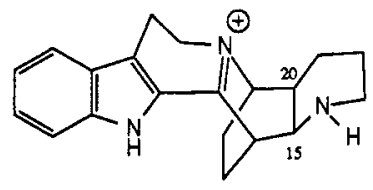

Allonitramidine $\underline{22}$

Nitramidine $\underline{21}$

SCHEME 5

Scheme 6 describes the synthesis of the reactive precursor 20 via glutarimide chemistry. In this case the required reduction steps of the glutarimide system are quite effective. Reactivity is introduced in the molecule via oxidation to the enamine moiety by mercuric acetate.

When the reaction mixture following cyclization is reduced in situ Nitrarine 27 and 3-Iso-allonitrarine are obtained directly. Reduction under more biological conditions with NADH models and application of the synthetic approach to Nitraramine and other Nitraria alkaloids is currently underway. 


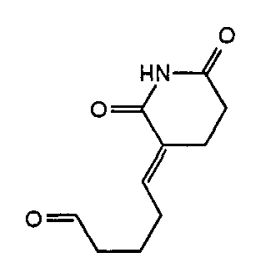

Glutarimide equivalent of the dipiperidine bioprecursor

$\underline{23}$
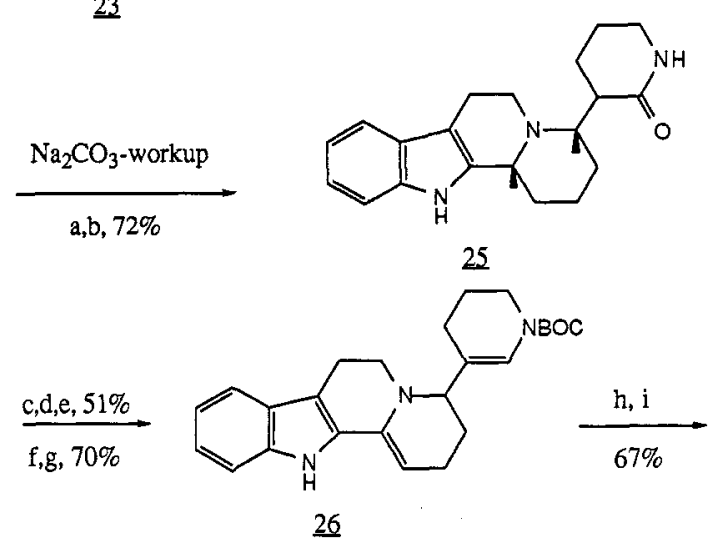

a) DiBAl-H, THF/DCM, $-18^{\circ}$,

b) $\mathrm{NaCNBH}_{3}, \mathrm{HOAc}, \mathrm{CH}_{3} \mathrm{CN}, 55^{\circ}, 2$ steps, $71 \%$

c) $\mathrm{BOC}_{2} \mathrm{O}, \mathrm{DMAP}(2 \mathrm{eq}),. \mathrm{DCM}$, reflux $84 \%$

d) $\mathrm{NaBH}_{4}, \mathrm{MeOH}, 0^{\circ}, 90 \%$

e) Pyr.TFA, toluene, reflux, $5 \mathrm{~min}, 68 \%$

f) $195-200^{\circ}$, neat, $10 \mathrm{~min}, 70 \%$

g) $\mathrm{Hg}(\mathrm{OAc})_{2}$.EDTA, $\mathrm{H}_{2} \mathrm{O}$, ethanol, $60^{\circ}, 1 \mathrm{~h}, 98 \%$

h) $5 \% \mathrm{HCl}, 85^{\circ}, 3 \mathrm{~h}$,

i) $\mathrm{NaBH}_{4}, \mathrm{MeOH}, \mathrm{O}^{\circ}, 2$ steps, $90 \%$

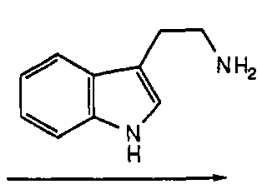

5 eq. TFA, DCM, $0^{\circ}$ $72 \%$

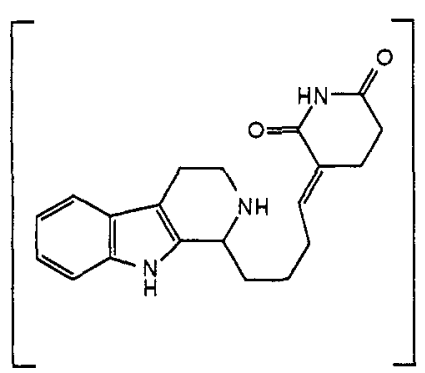

$\underline{24}$

2 crystalline isomers $(72: 28)$ at the glutarimide-carbon. The major isomer is shown.

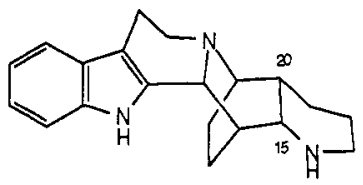

Nitrarine 27

$3: 5$

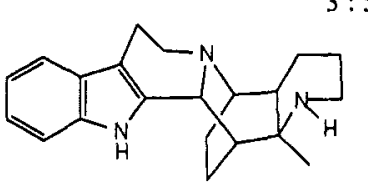

3-Iso-allonitrarine 28

SCHEME 6

\section{REFERENCES}

1a. Z. Osmanov, A.A. Ibragimov and S.Yu. Yunusov. Khim. Prir. Soedin.75, 126, 400 (1982) Chem. Nat. Compounds 18, 70, 121, 372 (1982).

b. A.A. Ibragimov and S. Yu. Yunusov. Khim. Prir. Soedin.730 (1986), 82 (1988). Chem. Nat. Compounds 22, 680 (1986), 24, 71 (1988).

2a. see 1 and B. Tashkodzhaev et al. Khim. Prir. Soedin 30 (1989). Chem. Nat. Compounds $\mathbf{2 5}, 24$ (1989).

b. S.-M. Nasirov et al. Khim. Prir. Soedin 334 (1976) . Chem. Nat. Compounds 12, 294 (1976).

3. P.N. Edwards and G.F. Smith. Proc. Chem. Soc. 215 (1960).

4. Y-Ch Kong, K.-F. Cheng, R.C. Cambie and P.G.Waterman.J.Chem.Soc. Chem.Commun. 47 (1985).

5. H.Weenen et al.J. Org. Chem. 55, 5107 (1990).

6. D.R. Dalton. Studies in Org. Chem. P.G. Gassman ed. 7, The Alkaloids. (Marcel Dekker Publ.) 4 ( 1979).

7. M.J. Wanner and G.J. Koomen. Adv. Nat. Prod. Chem. Atta-ur Rahman ed. (Harwood Ac. Publ.) 203 (1992).

M.J. Wanner and G.J. Koomen. Studies in Nat. Prod. Chem. Atta-ur Rahman ed. (Elsevier Publ.) 14, 731 (1993).

8. L. Üstünes et al.J. Nat. Products. 54, 959 (1991).

9. M.J. Wanner, A.J. Velzel and G.J. Koomen.J.Chem. Soc. Chem. Commun. 174 (1993). 